Diabetologia (1995) 38: 623-628

\title{
A new marker in the HLA class I region is associated with the age at onset of IDDM
}

\author{
A. G. Demaine, M. L. Hibberd, D. Mangles, B. A.Millward \\ Department of Medicine, Faculty of Postgraduate Medicine, University of Plymouth, Plymouth, UK
}

\begin{abstract}
Summary The (MHC) class II association with insulin-dependent diabetes mellitus (IDDM) is well documented. However, it is likely that genes within the MHC class III and the class I region also play a role in determining susceptibility to IDDM. In this study we have used a novel molecular probe to investigate the class I P3A and P3B loci of 179 patients with IDDM and 142 normal control subjects. A highly significant increase in the frequency of the class I P3 4.0;1.5 kilobase $(\mathrm{kb})$ and 4.0;1.8;1.5 kb genotypes was found in patients compared to the control subjects $\left(\chi^{2} 46.8,6 d f, p<0.0001\right)$. The association with the $\mathrm{P} 3 \mathrm{~B} 1.5 \mathrm{~kb}$ allele was strongly associated with the age at onset of diabetes, being present in $96.2 \%$
\end{abstract}

of subjects who developed diabetes between the age of 10-20 years compared to 55.0 and $74.6 \%$ who developed diabetes before 10 years or after 20 years, respectively $\left(\chi^{2} 31.4, p<0.0001\right)$. There was no evidence for linkage disequilibrium between the DQA1 and DQB1 loci and P3B suggesting that this is an independent association. In conclusion, these results suggest that genes in both the MHC class I and II regions confer susceptibility to IDDM and are related to the age at onset of the disease. [Diabetologia (1995) 38: 623-628]

Key words IDDM, major histocompatibility complex, immunogenetics, autoimmunity, HLA and disease.
Insulin-dependent diabetes mellitus (IDDM) is an autoimmune disease with a strong association to the serological markers HLA-DR3 and DR4 and to a lesser extent to HLA-B8, B15 and B18 [1-3]. Recent studies have shown that susceptibility is influenced by the substitution of an aspartic acid at position 57 of the DQB1 polypeptide chain, and the presence of an arginine residue at position 52 of the DQA1 polypeptide chain [4-6]. However, because of the strong disequilibrium across the (MHC) it is still unclear whether other loci may also contribute to the genetic background of this disease. For instance, it has previ-

Received: 29 July 1994 and in revised form: 22 November 1994

Corresponding author: Dr. A.G.Demaine, Department of Medicine, Faculty of Postgraduate Medicine, Davy Building, University of Plymouth, Plymouth, PLA 8AA, UK

Abbreviations: $\mathrm{kb}$, Kilobase; $\mathrm{SSC}, 0.3 \mathrm{~mol} / \mathrm{l}$ sodium chloride, $0.3 \mathrm{~mol} / 1$ sodium citrate; YAC, yeast artificial chromosome, $d f$, degrees of freedom. ously been shown that the $\mathrm{MHC}$ class III region (complement $\mathrm{C} 4$, heat shock protein 70 , tumour necrosis factor) may confer susceptibility to those individuals who are HLA-DR3/4 [7]. Recent serological and molecular typing of a large Finnish population suggests that the HLA-A alleles (MHC class I region) may be 'anchors' for disease-susceptibility haplotypes $[8,9]$. Finally, whilst previous studies have shown that the MHC class II association is dependent upon the age at onset of IDDM very little is known about the class I region [10-13].

We have used new DNA probes to investigate the $2000 \mathrm{~kb}$ class I region that lies between the HLA-B and -A loci (Fig. 1). The class I region is largely unexplored, but cloning of large fragments of DNA in yeast artificial chromosomes (YAC), in conjunction with pulsed field gel electrophoresis, has physically mapped the HLA-B, C, A and other loci [14, 15]. This greatly facilitates the identification of disease susceptibility loci in this area using molecular probes. In this report we present results using a novel 


\section{Class I Region}

CENTROMERE

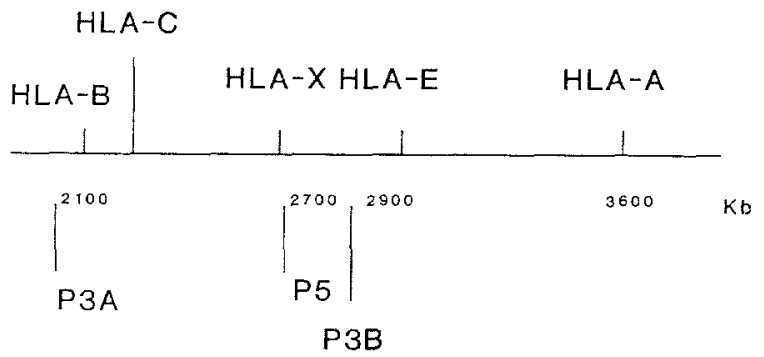

Fig. 1. Map of the human MHC class I region drawn approximately to scale. P3A and P3B are not thought to code for a functional gene; however, P5 is a member of a multiple copy gene family [14]. P3A, $40 \mathrm{~kb}+3.8 \mathrm{~kb}$ fragments. P3B, $650 \mathrm{~kb}$ telomeric to 88 , Pst $\mathrm{I}=1.8 \mathrm{~kb}+1.5 \mathrm{~kb}$ fragments. $\mathrm{P} 5,15$ $30 \mathrm{~kb}$ centromeric to P3B Hind III $=17 \mathrm{~kb}+14.5 \mathrm{~kb}$ fragments

marker to investigate a recently mapped part of the class I region in a large population of patients with IDDM.

\section{Subjects and methods}

Subjects. The study comprised 179 IDDM patients as defined by the National Diabetes Data Group [16] attending the Diabetic Clinic (Dr. B. A. Millward). Local ethical committee approval had been obtained. The patients had a duration of diabetes ranging from less than 1 year to more than 20 years; of these $33 \%$ had no evidence of microvascular complications.

The control subjects $(n=142)$ were normal British Caucasian blood donors residing in southern England with no history of IDDM or other autoimmune disease.

DNA preparation and hybridisation. High molecular weight DNA was prepared from $20 \mathrm{ml}$ of peripheral blood using standard proteinase-K digestion/phenol extraction. Of this DNA 5-10 $\mu \mathrm{g}$ was digested with 10-20 units of the appropriate restriction endonuclease following the manufacturer's protocol (Gibco-BRL, Paisley, UK). The DNA fragments were separated by size in $0.8 \%$ agarose gels and transferred and immobilised in nylon membranes (Hybond-N+, Amersham International, Amersham, Bucks., UK).

The membranes were hybridised for $16-20 \mathrm{~h}$ at $65^{\circ} \mathrm{C}$ (in a solution containing $6 \times \mathrm{SSC}, 5 \times$ Denhardt's solution, $5 \%$ dextran sulphate and $0.2 \mathrm{mg} / \mathrm{ml}$ denatured salmon sperm DNA) to a radioactive DNA probe prepared by the random primer technique. Washes to remove non-specifically bound probe were carried out at $65^{\circ} \mathrm{C}$, in $0.2 \times$ SSC, $0.5 \%$ SDS for $30-$ $40 \mathrm{~min}$. The hybridised membranes were placed between Cronex lightening plus intensifying screens with Kodak XAR5 film at $-80^{\circ} \mathrm{C}$. Films were developed after $1-5$ days.

DNA probe. The P3 probe was a $1.9 \mathrm{~kb}$ Pst-I fragment initially derived from the YAC 6F6, isolated from a YAC library constructed from a human cell line (HHK) homozygous for the HLA region [17]. This probe, in conjunction with the restriction endonuclease Pst-I, detects fragments of 4.0, 3.8, 1.8 and 1.5 kilobase $(\mathrm{kb})$. Combinations of these fragments give rise to at least nine different genotypes. The 4.0 and $3.8 \mathrm{~kb}$ fragments are alleles at the P3A locus which is $40 \mathrm{~kb}$ centromeric to HLA-B, whilst the 1.8 and $1.5 \mathrm{~kb}$ fragments are alleles at the $\mathrm{P} 3 \mathrm{~B}$ locus which is approximately $650 \mathrm{~kb}$ telomeric to HLA-B (Fig. 1).

HLA typing. HLA-A and HLA-B typing was carried out using standard microcytotoxicity assay and 9 th and 10th Workshop antisera. For class II typing, high molecular weight DNA was prepared from EDTA-peripheral blood using Nucleon kits (ScotLab, Paisley, UK). DQA1 and DQB1 alleles were identified using sequence specific oligonucleotide typing. Briefly, 300 ng of DNA was amplified using oligonucleotides specific for the second exon of either DQA1 or DQB1. The amplified DNA was electrophoresed through agarose, transferred to nylon membranes (Hybond-N+, Amersham International) and hybridised with a panel of $11 \mathrm{DQA} 1$ and $13 \mathrm{DQB} 1{ }^{32} \mathrm{P}$ radioactively labelled sequence specific oligonucleotides using protocols described previously [18].

\section{Statistical analysis}

The chi-squared test with contingency tables was used to determine the level of significance. Corrected $p$-values $(p c)$ were obtained by multiplying by the number of comparisons made. The Odds Ratios were calculated by the following formula: (patients with marker $\times$ control subjects without marker)/(patients without marker $\times$ control subjects with marker). The frequency of P3B-DQA1 and P3B-DQB1 haplotypes was calculated in those subjects who were homozygous at either the class I or II locus. The estimated haplotype frequency was obtained by multiplying the individual allelic frequencies. The chi-squared test was used to estimate linkage disequilibrium between the loci.

\section{Results}

The frequency of P3 genotypes in 179 patients and 142 normal healthy control subjects is shown in Table 1. Four of the nine P3 genotypes $(4.0 ; 1.8$, $4.0 ; 1.8 ; 1.5,4.0 ; 3.8 ; 1.8$ and $4.0 ; 3.8 ; 1.8 ; 1.5 \mathrm{~kb})$ accounted for more than $85 \%$ of the total number of genotypes detected in both the patient and normal control populations. There was a highly significant increase in the frequency of the 4.0;1.5 and $4.0 ; 1.8 ; 1.5 \mathrm{~kb}$ P3 genotypes in the patient population compared to the control subjects $\left(\chi^{2} 46.8,6 d f\right.$, $p<0.0001, p c=0.0009$, Odds Ratio 7.2 and 2.3, respectively). This was accompanied by decreased frequencies of the $4.0 ; 1.8$ and $4.0 ; 3.8 ; 1.8 \mathrm{~kb}$ P3 genotypes. The P3B $1.5 \mathrm{~kb}$ allele was present in $79.9 \%$ of patients compared with $50.0 \%$ of control subjects $\left(\chi^{2} 31.9, p<0.0001, p c=0.0009\right.$, Odds Ratio 3.25).

The patient population was separated into three groups depending upon the age at onset: less than 10 years $(n=40), 10-20(n=80)$ years and more than 20 years $(n=59)$. The frequency of the P3 genotypes in these three groups is shown in Table 2. There was a highly significant difference in the frequency of the four common $\mathrm{P} 3$ genotypes between the three patient 
Table 1. Frequency (\%) of MHC class I P3 genotypes in IDDM and normal control subjects

\begin{tabular}{|c|c|c|c|}
\hline \multicolumn{2}{|c|}{ Genotype (kb) } & \multirow{2}{*}{$\begin{array}{l}\text { Patients } \\
\overline{\%(n)}\end{array}$} & \multirow{2}{*}{$\begin{array}{l}\text { Control } \\
\text { subjects }\end{array}$} \\
\hline & & & \\
\hline P3A locus & P3B locus & $(n=179)$ & $(n=142)$ \\
\hline 4.0 & 1.8 & $7.3^{\mathrm{a}}(13)$ & $22.5(32)$ \\
\hline 4.0 & 1.5 & $17.3^{\mathrm{a}}(31)$ & $2.8(4)$ \\
\hline 4.0 & $1.8 ; 1.5$ & $34.1^{\mathrm{a}}(61)$ & $18.3(26)$ \\
\hline $4.0 ; 3.8$ & 1.8 & $10.6^{\mathrm{a}}(19)$ & $24.6(35)$ \\
\hline $4.0 ; 3.8$ & 1.5 & $3.3(6)$ & $2.8(4)$ \\
\hline $4.0 ; 3.8$ & $1.8 ; 1.5$ & $24.0(43)$ & $21.1(30)$ \\
\hline 3.8 & $1.8 ; 1.5$ & $0.6(1)$ & $3.5(5)$ \\
\hline 3.8 & 1.8 & $2.2(4)$ & $2.8(4)$ \\
\hline 3.8 & 1.5 & $0.6(1)$ & $1.4(2)$ \\
\hline \multicolumn{2}{|c|}{ All 4.0 subjects } & 96.6 & 92.2 \\
\hline \multicolumn{2}{|c|}{ All 1.5 subjects } & $79.9^{\mathrm{b}}$ & 50.0 \\
\hline
\end{tabular}

${ }^{a}$ Difference in frequency of genotypes between patients and controls; $\chi^{2} 46.8(6 d f), p<0.0001, p c=0.0009$. Odds ratios for the $4.0 ; 1.5$ and $4.0 ; 1.8 ; 1.5 \mathrm{~kb} \mathrm{P3B}$ genotypes are 7.2 and 2.3 , respectively;

${ }^{\mathrm{b}}$ vs frequency in control subjects $\chi^{2} 31.9, p<0.0001$. The P3 probe in conjunction with the Pst-I detects allelic fragments of 4.0, 3.8 (corresponding to the P3A locus), 1.8 and $1.5 \mathrm{~kb}$ of the $\mathrm{P} 3 \mathrm{~B}$ locus

Table 2. Frequency (\%) of MHC class I P3 genotypes with respect to age at onset of IDDM

\begin{tabular}{|c|c|c|c|c|}
\hline \multicolumn{2}{|c|}{ Genotype $(\mathrm{kb})$} & \multicolumn{3}{|c|}{ Age at onset of diabetes (years) } \\
\hline & & $<10$ & $10-20$ & $>20$ \\
\hline P3A locus & P3B locus & $(n=40)$ & $(n=80)$ & $(n=59)$ \\
\hline 4.0 & 1.8 & $12.5(5)$ & $2.5(2)$ & $10.2(6)$ \\
\hline 4.0 & 1.5 & $7.5^{\mathrm{a}}(3)$ & $20.0^{\mathrm{b}}(16)$ & $20.3^{c}(12)$ \\
\hline 4.0 & $1.8 ; 1.5$ & $27.5^{\mathrm{a}}(11)$ & $38.7(31)$ & $32.2(19)$ \\
\hline $4.0 ; 3.8$ & 1.8 & $30.0^{\mathrm{a}}(12)$ & $1.2(1)$ & $10.2(6)$ \\
\hline $4.0 ; 3.8$ & 1.5 & $5.0(2)$ & $3.8(3)$ & $1.7(1)$ \\
\hline $4.0 ; 3.8$ & $1.8 ; 1.5$ & $15.0^{\mathrm{a}}(6)$ & $31.2(25)$ & $20.3(12)$ \\
\hline 3.8 & $1.8 ; 1.5$ & $0.0(0)$ & $1.2(1)$ & $0.0(0)$ \\
\hline 3.8 & 1.8 & $2.5(1)$ & $0.0(0)$ & $5.1(3)$ \\
\hline 3.8 & 1.5 & $0.0(0)$ & $1.2(1)$ & $0.0(0)$ \\
\hline \multirow{2}{*}{\multicolumn{2}{|c|}{$\begin{array}{l}\text { All } 4.0 \text { subjects } \\
\text { All } 1.5 \text { subjects }\end{array}$}} & $97.5(39)$ & $97.5(78)$ & $94.9(56)$ \\
\hline & & $55.0(22)$ & $96.2^{d}(77)$ & $74.6(44)$ \\
\hline
\end{tabular}

subgroups $\left(\chi^{2} 29.3(8 d f, p<0.0005, p c=0.001)\right.$. The $4.0 ; 1.5$ and $4.0 ; 3.8 ; 1.8 ; 1.5 \mathrm{~kb}$ P3 genotypes were reduced in those patients with an age at onset of less than 10 years compared to the other two subgroups (22.5 vs $46.7 \%$, respectively). The $4.0 ; 3.8 ; 1.8 \mathrm{~kb} \mathrm{P3}$ genotype was markedly increased in the patient subgroup with the youngest age at onset compared to either of the other two patient subgroups (30.0 vs 1.2 and $10.2 \%$, respectively, $\chi^{2} 23.6,3 d f, p<0.0005, p \mathrm{c}$ $=0.006$ ). The P3B $1.5 \mathrm{~kb}$ allele was found in $96.2 \%$ of patients who presented between the age of 10
Tahle 3. Frequency (\%) of MHC class I P3B - class II DQA1 haplotypes

\begin{tabular}{|c|c|c|c|c|c|}
\hline \multirow{2}{*}{$\begin{array}{l}\text { P3B-DQA1 } \\
\text { haplotype }\end{array}$} & \multicolumn{2}{|c|}{ Observed } & \multicolumn{2}{|c|}{ Expected } & \multirow{2}{*}{$\begin{array}{l}\text { chi- } \\
\text { squared }\end{array}$} \\
\hline & $n$ & Freq & $n$ & Freq & \\
\hline $1.5-0101$ & 3 & 1.8 & 7.0 & 4.2 & 2.29 \\
\hline 1.8-0101 & 11 & 6.6 & 7.0 & 4.2 & 2.29 \\
\hline $1.5-0301$ & 32 & 19.3 & 37.5 & 22.6 & 0.81 \\
\hline $1.8-0301$ & 43 & 25.9 & 37.5 & 22.6 & 0.81 \\
\hline $1.5-0501$ & 41 & 24.7 & 31.5 & 19.0 & 2.86 \\
\hline $1.8-0501$ & 22 & 13.2 & 31.5 & 19.0 & 2.86 \\
\hline $1.5-\mathrm{X}$ & 7 & 4.2 & 7.0 & 4.2 & 0.001 \\
\hline $1.8-\mathrm{X}$ & 7 & 4.2 & 7.0 & 4.2 & 0.001 \\
\hline
\end{tabular}

$\mathrm{X}$, Non-DQA $1 * 0101,0301$ or 0501.166 haplotypes were assigned in subjects who were homozygous at more than one locus

Table 4. Frequency (\%) of MHC class I P3B - class II DQB1 haplotypes

\begin{tabular}{|c|c|c|c|c|c|}
\hline \multirow{2}{*}{$\begin{array}{l}\text { P3B-DQB1 } \\
\text { haplotype }\end{array}$} & \multicolumn{2}{|c|}{ Observed } & \multicolumn{2}{|c|}{ Expected } & \multirow{2}{*}{$\begin{array}{l}\text { chi- } \\
\text { squared }\end{array}$} \\
\hline & $n$ & Freq & $n$ & Freq & \\
\hline $1.5-0201$ & 46 & 28.4 & 37.5 & 23.1 & 1.93 \\
\hline $1.8-0201$ & 29 & 17.9 & 37.5 & 23.1 & 1.93 \\
\hline $1.5-0301$ & 6 & 3.7 & 9.0 & 5.6 & 1.0 \\
\hline 1.8-0301 & 12 & 7.4 & 9.0 & 5.6 & 1.0 \\
\hline $1.5-0302$ & 20 & 12.3 & 21.5 & 13.3 & 0.1 \\
\hline $1.8-0302$ & 23 & 14.2 & 21.5 & 13.3 & 0.1 \\
\hline $1.5-0501$ & 2 & 1.2 & 6.5 & 4.0 & 3.12 \\
\hline $1.8-0501$ & 11 & 6.8 & 6.5 & 4.0 & 3.12 \\
\hline $1.5-\mathrm{X}$ & 7 & 4.3 & 6.5 & 4.0 & 0.04 \\
\hline $1.8-X$ & 6 & 3.7 & 6.5 & 4.0 & 0.04 \\
\hline
\end{tabular}

$\mathrm{X}$, Non-DQB1*0201, 0301, 0302, 0501.162 haplotypes were assigned in those subjects who were homozygous at more than one locus

20 years (Odds Ratio 25.7) compared to only $55 \%$ of those presenting before the age of 10 years (Odds Ratio 1.2) $\left(\chi^{2} 31.4, p<0.0001, p c=0.001\right)$. In contrast, 79.0 and $72.7 \%$ of the subjects in these patient groups had either a DQB1*0201 or 0302 allele or both. Twelve of the 13 patients in the 10-20 years age at onset group who had neither a DQB1*0201 or 0302 allele possessed at least one P3B $1.5 \mathrm{~kb}$ allele compared to only one out of six patients in the group presenting before the age of 10 years. Only one patient in the $10-$ 20 years age at onset group had neither the P3B $1.5 \mathrm{~kb}$ allele nor DQB $1 * 0201$ nor a 0302 allele.

The frequency of 166 P3B-DQA1 and 162 P3BDQB1 haplotypes (Tables 3 and 4, respectively) was determined in those subjects who were homozygous at either the P3B, DQA1 or DQB1 loci. The expected haplotype frequencies were obtained from the allelic frequencies and used to calculate linkage between the P3B and either the DQA1 or DQB1 loci. Overall, there was no significant difference between the observed and expected P3B-DQA1 haplotypes (Table 3 ). There was a trend for the DQA $1 * 0101$ allele to be found more frequently with the P3B $1.8 \mathrm{~kb}$ allele and the DQA1*0501 allele to be present with 
the P3B $1.5 \mathrm{~kb}$ allele. No trend was found with the DQA1*0301 allele. Table 4 shows a similar analysis of the P3B-DQB1 haplotypes. Again no significant difference was found between the observed and expected haplotype frequencies although the DQB1*0201 and DQB1*0501 alleles were found more frequently with the $\mathrm{P} 3 \mathrm{~B} 1.5 \mathrm{~kb}$ and $\mathrm{P} 3 \mathrm{~B} 1.8 \mathrm{~kb}$ alleles, respectively. The DQB $1 * 0301$ and DQB $1 * 0302$ alleles showed no evidence of preferentially associating with a particular P3B allele.

Tables 5 and 6 show the frequency of class I P3 genotypes in 126 subjects where HLA-A and HLA-B serological typing was carried out. There was a trend for the HLA-A1 and -A2 antigens to be found more frequently with those $\mathrm{P} 3$ genotypes containing the P3B $1.5 \mathrm{~kb}$ allele (Table 5). In contrast, of the 25 subjects who were HLA-A3, only one was homozygous for the $\mathrm{P} 3 \mathrm{~B} 1.5 \mathrm{~kb}$ allele whilst 14 were homozygous for the P3B $1.8 \mathrm{~kb}$ allele. Table 6 shows the frequency of HLA-B7, -B8 and -B12 with respect to P3 genotypes. Fourteen out of 21 subjects who were HLA-B7 were homozygous for the $\mathrm{P} 3 \mathrm{~B} 1.8 \mathrm{~kb}$ allele; none were homozygous for the P3B $1.5 \mathrm{~kb}$ allele (Table 6). Homozygosity for the P3B $1.8 \mathrm{~kb}$ allele was found in 24 of $46 \mathrm{HLA}-\mathrm{B} 12$ positive subjects whilst 0 of 46 were homozygous for the P3B $1.5 \mathrm{~kb}$ allele. Finally, only 2 of 25 HLA-B8 positive subjects were homozygous for the P3B $1.8 \mathrm{~kb}$ allele compared to 10 of 25 homozygous for the $1.5 \mathrm{~kb}$ allele. There were insufficient numbers to analyse the P3B genotypes with other HLA antigens.

\section{Discussion}

We have identified a new marker within the MHC class I region which is strongly associated with IDDM and age at onset of this disease. The P3B locus is located approximately $650 \mathrm{~kb}$ telomeric of HLA-B in a newly-explored area of the class I region. Previous studies have suggested that the class III region may harbour disease susceptibility loci and it has been suggested that the tumour necrosis factor (TNF) - HLA-B sub-region to be of particular importance $[7,19,20]$. However, this is the first study using molecular typing to investigate the region telomeric of HLA-B and our results have extended the area which may contain susceptibility genes. Whilst the P3B locus does not itself encode a protein, a novel member of a multiple copy gene family which codes for polypeptide sequences distinct from class I has previously been mapped in close proximity to it [21]. Recently, a gene coding for a putative GTPbinding protein HSR1 as well as tubulin-B have also mapped close to HLA-E and the P3B locus [22, 23]. The HLA-E locus is less than $100 \mathrm{~kb}$ telomeric of P3B (Fig. 1) and whilst its function is still unknown it has been shown to be capable of binding peptides, al-
Table 5. Relationship of MHC class I P3 genotypes to HLA-A antigen

\begin{tabular}{|c|c|c|c|c|c|c|c|}
\hline \multicolumn{2}{|c|}{$\begin{array}{l}\text { P3 Genotype } \\
\text { (kb) }\end{array}$} & \multicolumn{6}{|c|}{ HLA-A antigen } \\
\hline \multirow[t]{2}{*}{ P3A } & \multirow[t]{2}{*}{$\mathrm{P} 3 \mathrm{~B}$} & \multicolumn{2}{|c|}{ HLA-A1 } & \multicolumn{2}{|c|}{ HLA-A2 } & \multicolumn{2}{|c|}{ HLA-A3 } \\
\hline & & + & - & + & - & + & - \\
\hline 4.0 & 1.5 & 17.4 & 3.7 & 11.9 & 5.1 & 0.0 & 10.9 \\
\hline 4.0 & 1.8 & 15.2 & 23.8 & 17.9 & 23.7 & 32.0 & 17.8 \\
\hline 4.0 & $1.8 ; 1.5$ & 15.2 & 17.5 & 17.9 & 15.2 & 20.0 & 15.8 \\
\hline $4.0 ; 3.8$ & 1.5 & 4.3 & 1.2 & 1.5 & 3.4 & 4.0 & 2.0 \\
\hline $4.0 ; 3.8$ & 1.8 & 17.4 & 25.0 & 22.4 & 25.4 & 24.0 & 23.8 \\
\hline \multirow[t]{2}{*}{$4.0 ; 3.8$} & $1.8 ; 1.5$ & 28.3 & 18.8 & 20.9 & 20.3 & 20.0 & 20.8 \\
\hline & Other & 2.2 & 10.0 & 7.5 & 6.9 & 0.0 & 8.9 \\
\hline$(n)$ & & $(46)$ & $(80)$ & $(67)$ & (59) & $(25)$ & (101) \\
\hline
\end{tabular}

$(+)$ and $(-)$ denote presence or absence of either HLA-A1, HLA-A2 or HLA-A3

Table 6. Relationship of MHC class I P3 genotypes to HLA-B antigen

\begin{tabular}{|c|c|c|c|c|c|c|c|}
\hline \multicolumn{2}{|c|}{$\begin{array}{l}\text { P3 Genotype } \\
(\mathrm{kb})\end{array}$} & \multicolumn{6}{|c|}{ HLA-B antigen } \\
\hline \multirow[t]{2}{*}{ P3A } & \multirow[t]{2}{*}{ P3B } & \multicolumn{2}{|c|}{ HLA-B7 } & \multicolumn{2}{|c|}{ HLA-B8 } & \multicolumn{2}{|c|}{ HLA-B12 } \\
\hline & & + & - & + & - & + & - \\
\hline 4.0 & 1.5 & 4.8 & 9.5 & 36.0 & 2.0 & 0.0 & 13.7 \\
\hline 4.0 & 1.8 & 33.3 & 18.1 & 4.0 & 24.0 & 23.9 & 18.7 \\
\hline 4.0 & $1.8 ; 1.5$ & 23.8 & 16.2 & 28.0 & 15.9 & 15.2 & 20.0 \\
\hline $4.0 ; 3.8$ & 1.5 & 0.0 & 2.9 & 4.0 & 1.0 & 0.0 & 2.5 \\
\hline $4.0 ; 3.8$ & 1.8 & 28.6 & 20.0 & 4.0 & 27.1 & 28.3 & 18.7 \\
\hline $4.0 ; 3.8$ & $1.8 ; 1.5$ & 9.5 & 24.8 & 24.0 & 20.9 & 19.6 & 22.5 \\
\hline & Other & 0.0 & 8.6 & 0.0 & 9.1 & 13.0 & 3.7 \\
\hline (n) & & (21) & $(105)$ & $(25)$ & $(101)$ & $(46)$ & $(80)$ \\
\hline
\end{tabular}

$(+)$ and $(-)$ denote presence or absence of either HLA-B7, HLA-B8 or HLA-B12

beit inefficiently [24], although it does not appear to be polymorphic. It is highly likely that in the future other genes will also be found in this region. Fortunately, organisation of the class I region is rapidly being established which will enable new markers to be developed. The MHC class I region has also been implicated in studies investigating the autoimmune destruction of the islet beta-cells. Hyperexpression of MHC class I molecules on the surface of islets as well as the presence of cytotoxic $T$ cells within the lesion have been reported [25]. In addition, Japanese patients with IDDM with HLA-A24 have a complete loss of beta-cell function and an acute onset of the disease $[26,27]$.

The results obtained confirm and extend previous reports suggesting that the class $I$ as well as the class II region contributes to the genetic susceptibility to IDDM [1, 8, 9]. The P3B 1.5 and $1.8 \mathrm{~kb}$ alleles showed no significant linkage with the class II DQA1 or DQB1 alleles suggesting that it is an independent marker. There was an excess of the $\mathrm{P} 3 \mathrm{~B}$ $1.5 \mathrm{~kb}$ allele in those subjects who did not have the 
class II susceptibility alleles DQB1*0201 or DQB $1 * 0302$ and developed diabetes between the age of 10-20 years. These findings were reversed in those patients diagnosed before the age of 10 years where there was an excess of the class II DQB $1 * 0201$ and DQB1*0302 alleles. The results in the 10-20 year age group are similar to the results reported in a Finnish population where patients who are unable to form a 'diabetes-susceptibility' DQ heterodimer tend to have two copies of a HLA-A allele associated with IDDM [9]. This suggests that the influence of the class I or II susceptibility loci varies according to age at onset of the disease - the class II region being important in early childhood and the class I region in older groups. Further, IDDM in young children who are HLA-DR3/DR4 is characterised by reduced residual beta-cell function, a clinical remission of short duration and impaired metabolic control [10,13]. This group also has higher titre insulin and islet cell antibodies compared to those who develop the disease at a later age. Consequently, it is likely that there are different environmental triggers in each of these groups. For instance, evidence is accumulating that early exposure of an infant to cow's milk proteins and solids can increase the risk of IDDM [28, 29]. This environmental trigger may be important in young children whilst those who develop diabetes at a later age may have been exposed to additional environmental factors. It is tantalising to suggest that those subjects who develop diabetes at an early age have an autoimmune response which is driven by the humoral arm of the immune system. In contrast, in those individuals who develop diabetes at a later age the anti-islet-cell response is dominated by the cellular arm of the immune system. Alternatively, the results may reflect different rates of disease progression which is determined by genes in both the MHC class I and II regions [30]. Studies of immunological changes during the 'pre-diabetic' period have shown variability in the rate of progression to IDDM. Further studies are now required to address these points and map precisely the association with the class I region.

Acknowledgements. We would like to thank Dr. P.Pontarotti for kindly supplying the class I probes and to Dr. C.Lynas and Ms.P.Doxsey for advice and technical support. This work was funded by the British Diabetic Association.

\section{References}

1. Cudworth AG, Woodrow JC (1976) Genetic susceptibility in diabetes mellitus: analysis of the HLA association. B M J 2: 846-848

2. Platz P, Jakobsen BK, Morling N et al. (1981) HLA-D and -DR antigens in the genetic analysis of insulin-dependent diabetes mellitus. Diabetologia 21: 108-115

3. Wolf E, Spencer KM, Cudworth AG (1983) The genetic susceptibility of type I (insulin dependent) diabetes: analysis of the HLA-DR association. Diabetologia 24: 224-230

4. Todd JA, Bell JI, McDevitt HO (1987) HLA-DQ $\beta$ gene contributes to susceptibility and resistance to insulin-dependent diabetes mellitus. Nature 329: 599-604

5. Horn G, Bugawan D, Long C, Erlich HA (1988) Allelic sequence variation of the HLA-DQ loci: relationships to serology and to insulin-dependent diabetes susceptibility. Proc Natl Acad Sci 85: 6012-6016

6. Khalil I, d'Auriol K, Gobet M et al. (1990) A combination of HLA-DQ beta Asp-57 negative and HLA-DQ alpha Arg-52 confers susceptibility to insulin-dependent diabetes mellitus. J Clin Invest 85: 1315-1319

7. Thomsen M, Molvig J, Zerbib A et al. (1988) The susceptibility to insulin-dependent diabetes mellitus is associated with C4 allotypes independently of the association with HLA-DQ alleles in HLA-DR3,4 heterozygotes. Immunogenetics 28: 320-327

8. Tienari PJ, Tuomilehto-Wolf E, Tuomilehto J, Peltonen L and the DIME Study Group (1992) HLA haplotypes in type I (insulin-dependent) diabetes mellitus: molecular analysis of the HLA-DQ locus. Diabetologia 35: 254--260

9. Fennessy M, Metcalfe K, Hitman GA et al. (1994) A gene in the HLA class I region contributes to susceptibility to IDDM in the Finnish population. Diabetologia 37: 937944

10. Knip M, Ilonen J, Mustonen A, Akerblom HK (1986) Evidence of an accelerated $\beta$-cell destruction in HLA-Dw3/ Dw4 heterozygous children with type I (insulin dependent) diabetes. Diabetologia 29: 347-351

11. Ludvigsson J, Samuelsson U, Beauforts C et al. (1986) HLA-DR3 is associated with a more slowly progressive form of type I (insulin-dependent) diabetes. Diabetologia 29: $207-210$

12. Caillat-Zucman S, Garchon H-J, Timsit J et al. (1992) Agedependent HLA genetic heterogeneity of type I insulin-dependent diabetes mellitus. J Clin Invest 90: 2242-2250

13. Karjalainen J, Salmela P, Ilonen J, Surcel H-M, Knip M (1989) A comparison of childhood and adult type I diabetes mellitus. New Engl J Med 320: 881-886

14. Chimini G, Boretto J, Marguet D, Lanau F, Lauquin G, Pontarotti P (1990) Molecular analysis of the human MHC class I region using yeast artificial chromosome clones. Immunogenetics 32: 419-426

15. Abderrahim H, Sambucy J-L, Iris F et al. (1994) Cloning the human major histocompatibility complex in YACs. Genomics 23: 526-527

16. National Diabetes Data Group (1979) Classification and diagnosis of diabetes mellitus and other categories of glucose intolerance. Diabetes 28: 1039-1057

17. David V, Boretto J, Jouanolle AM et al. (1990) Two polymorphisms at the locus D698 defined by a YAC. Nucl Acid Res 18: 5582

18. Doherty DG, Vaughan RW, Donaldson PT, Mowat AP (1992) HLA-DQA, DQB and DRB genotyping by oligonucleotide analysis: distribution of alleles and haplotypes in British Caucasoids. Human Immunol 34: 53-63

19. Caplen NJ, Patel A, Millward A et al. (1990) Complement $\mathrm{C} 4$ and heat shock protein 70 (HSP70) genotypes and type I diabetes mellitus. Immunogenetics 32: 427-430

20. Degli-Esposti MA, Andreas A, Christiansen FT, Schalke B, Albert E, Dawkins RL (1992) An approach to the localisation of the susceptibility genes for generalised myasthenia gravis by mapping recombinant ancestral haplotypes. Immunogenetics 35: 355-364

21. Vernet C, Ribouchon M-T, Chimini G, Jouanolle A-M, Sidibe I, Pontarotti P (1993) A novel coding sequence be- 
longing to a new multicopy gene family mapping within the human MHC class I region. Immunogenetics 38: 47-53

22. Vernet C, Ribouchon M-T, Chimini G, Pontarotti P (1994) Structure and evolution of a member of a new subfamily of GTP-binding proteins mapping to the human MHC class I region. Mamm Genome 5: 100-105

23. Volz A, Weiss E, Trowsdale J, Ziegler A (1994) Presence of an expressed $\beta$-tubulin gene (TUBB) in the HLA class I region may provide the genetic basis for HLA-linked microtubule dysfunction. Human Genetics 93: 42-46

24. Ulbrecht M, Kellermann J, Johnson JP, Weiss EH (1992) Impaired intracellular transport and cell surface expression of non-polymorphic HLA-E: evidence for inefficient peptide binding. J Exp Med 176: 1083-1090

25. Bottazzo GF, Dean BM, McNally JM et al. (1985) In situ characterisation of autoimmune phenomena and expression of HLA molecules in diabetic insulitis. New Engl J Med 313: 353-360
26. Nakanishi K, Kobayashi T, Murase Tet al. (1993) Association of HLA-A24 with complete $\beta$-cell destruction in IDDM. Diabetes 42: 1086-1093

27. Kobayashi T, Tamemoto K, Nakanishi K, Kato N, Okubo M (1993) Immunogenetic and clinical characterisation of slowly progressive IDDM. Diabetes Care 16: 780-788

28. Virtanen SM, Rasanen L, Ylonen K et al. (1993) Early introduction of dairy products associated with increased risk of IDDM in Finnish children. Diabetes 42: 1786-1790

29. Gerstein HC (1994) Cow's milk exposure and type I diabetes. Diabetes Care 17: 13-19

30. Ziegler AF, Ziegler R, Vardi P, Jackson RA, Soeldner JS, Eisenbarth GS (1989) Life-table analysis of progression to diabetes of anti-insulin autoantibody positive relative of individuals with type I diabetes. Diabetes 38: 1320-1325 